\title{
Synthesis and Structural Characterisation of the Copper MOF: STAM-NMe 2
}

Received 00th January 20xx, Accepted 00th January 20xx DOI: $10.1039 / \times 0 \times x 00000 x$

\author{
Lauren N. McHugh, ${ }^{* a}$ Leonardo J. Olivera Perez, ${ }^{b}$ Paul S. Wheatley, ${ }^{a}$ David B. Cordes, ${ }^{a}$ Alexandra
} M. Z. Slawin, ${ }^{a}$ and Russell E. Morris ${ }^{a}$
Here we demonstrate the synthesis and structural characterisation of a novel copper MOF: STAM-NMe using the linker 5-dimethylamino isophthalic acid. The material is a member of the STAM series of MOFs, with a Kagome lattice structure and contains two types of pore system. The structure was investigated using single crystal $X$-ray diffraction, variable temperature powder $\mathrm{X}$-ray diffraction was used to determine the thermal stability of the MOF, and nitrogen BET adsorption was employed to determine the porosity of the material.

\section{Introduction}

Metal-organic frameworks (MOFs) are of great interest in the fields of biomedicine, ${ }^{1-3}$ catalysis, ${ }^{4}$ sensing, ${ }^{5}$ luminescence, ${ }^{6,7}$ separation, ${ }^{8}$ gas adsorption and release, ${ }^{9-12}$ and have recently been highlighted as promising materials in the field of air purification. ${ }^{13-16}$ MOFs have received attention in these areas due to their high porosities, ${ }^{17,18}$ resistance to residual and coordinated solvent loss, ${ }^{19,20}$ and consequently the availability of coordinatively unsaturated sites (CUS) for the adsorption of guest molecules. ${ }^{21-23}$ Many metals have been used in MOF synthesis, though copper MOFs are chemically suitable for the adsorption of small molecules such as ammonia and hydrogen sulfide due to the strong interactions formed between the framework and the adsorbent. ${ }^{24}$ The first member in a series of copper MOFs named the STAM (St Andrews MOF) series was STAM-1,25 which was developed within the Morris group and displays two types of accessible channel, with excellent gas adsorption properties. The structure and properties of another member of the STAM series: STAM-17-OEt was recently reported, ${ }^{26}$ which showed excellent hydrolytic

\footnotetext{
a. School of Chemistry, North Haugh, University of St Andrews, St Andrews, Fife, KY16 9ST, UK

*E-mail:Im83@st-andrews.ac.uk

${ }^{b}$ Department of Chemistry, Johns Hopkins University, Remsen Hall, 3400 N Charles St, Baltimore, MD 21218, USA.

tElectronic Supplementary Information (ESI) available: CCDC 1938059. For ESI and crystallographic data in $\mathrm{CIF}$ or other electronic format see DOI: $10.1039 / x 0 x \times 00000 x$
}

stability and uptake of the toxic inorganic chemical ammonia. The STAM materials have a dual pore structure, consisting of hydrophilic and hydrophobic pores, which leads to switchable and controllable adsorption properties.

Members of the STAM series typically have an oxygencontaining side chain which protrudes into the hydrophobic pore. In this manuscript, we report the synthesis, structure and properties of a new copper MOF, with STAM topology that contains a dimethylamino side chain.

\section{Experimental}

STAM-NMe $\mathrm{N}_{2}$ synthesis: 5 -dimethylamino isophthalic acid $(0.11$ $\mathrm{g}, 0.53 \mathrm{mmol}$ ) and copper acetate monohydrate $(0.10 \mathrm{~g}, 0.50$ $\mathrm{mmol}$ ) were suspended in distilled water $(7.5 \mathrm{~mL})$ inside the Teflon liner of a stainless steel autoclave. The sealed autoclave was placed in an oven at $110{ }^{\circ} \mathrm{C}$ for 4 days. Upon cooling, the contents were filtered and washed with distilled water and ethanol before drying in air to provide a green, crystalline solid ( $0.10 \mathrm{~g}, 0.35 \mathrm{mmol}, 70 \%$ yield). Linker synthesis may be found in the associated ESIt.

Data were collected at $173 \mathrm{~K}$ on a Rigaku FR-X Ultra-high brilliance diffractometer with Mo $K \alpha$ radiation source $(\lambda=$ $0.71073 \AA$ ) and a RigakuXtaLAB P200 detector. Absorption corrections were applied using multi-scan methods in CrysAlisPro 1.171.38.46. ${ }^{27}$ The structure solution was obtained using SHELXT ${ }^{28}$ and refined by full matrix on $F^{2}$ using SHELXL ${ }^{29}$ within the Olex2 $2^{30}$ suite. All full occupancy non-hydrogen atoms were refined with anisotropic thermal displacement parameters. Aromatic hydrogen atoms and hydrogen atoms belonging to coordinated water molecules were included at their geometrically estimated positions and disordered solvent molecules present in the hydrophilic pores were masked during the refinement.

Powder X-ray diffraction (PXRD) was collected on a STOE STADIP primary beam monochromator diffractometer using $\mathrm{Cu}$ $\mathrm{K} \alpha_{1}$ radiation in glass capillaries at $298 \mathrm{~K}$. Structure refinement was performed using the GSAS analysis software ${ }^{31}$ and the 
EXPGUI graphical user interface. ${ }^{32}$

Variable temperature PXRD was collected under vacuum on a PANalytical Empyrean X'celerator RTMS detector diffractometer using $\mathrm{Mo} K \alpha_{1,2}$ radiation in an alumina sample holder.

Thermal gravimetric analysis (TGA) was performed in air, using a Netzsch Thermogravimetric Analyzer TG 209 from ambient temperature to $700{ }^{\circ} \mathrm{C}$, with a $10^{\circ} \mathrm{C}$ per minute heating rate. Nitrogen BET (Brunauer-Emmett-Teller) surface area analysis was performed on a Micromeritics ASAP 2020 surface area and porosity analyser, where samples (ca. $100 \mathrm{mg}$ ) were activated under vacuum at room temperature or $100{ }^{\circ} \mathrm{C}$ for approximately 16 hours prior to dosing with nitrogen gas at 77 K.

\section{Results and Discussion}

STAM-NMe $\mathrm{N}_{2}$ was prepared hydrothermally and yielded green block crystals in good yield (70\%). The crystals obtained from the bulk batch were of sufficient size and quality for in-house single crystal analysis, and PXRD measurements show that the pattern of the as-made material matches the simulated powder pattern obtained crystallographically from the cif file, where only coordinated water molecules were modelled (Fig. 1). The difference in intensity between the first peaks in the experimental and simulated patterns may be due to preferential orientation effects from the preparation of powder samples in the experimental pattern, compared to the ideal powder in the simulated pattern.

The bulk material was compared to the single crystal phase to confirm sample purity by a whole-

pattern (Le Bail type) refinement of the unit cell against the $X$ ray diffraction data (Fig. S1 and Table S1). The final R-values were $R_{p}=5.29 \%$ and $w R_{p}=6.43 \%$. Minor differences in the unit cell dimensions were observed between the calculated and observed pattern due to the different collection

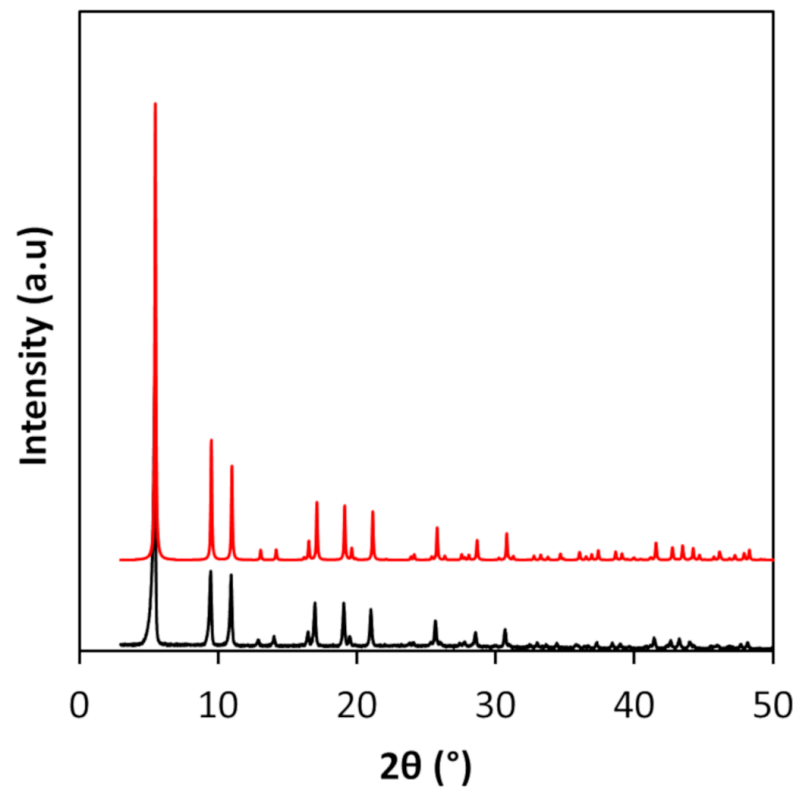

Fig. 1 Comparison of as made PXRD pattern (black line) and the simulated pattern from single crystal data (red line). temperatures of the single crystal data and powder data.

Crystals of STAM-NMe ${ }_{2}$ have a Kagome lattice structure ${ }^{33}$ and STAM topology, in the trigonal space group $P \overline{3} m 1$ with unit cell dimensions of $\mathrm{a}=18.5382(5) \AA$ and $\mathrm{c}=6.7599(2) \AA$. The final $R$-values were $R_{1}=3.67 \%$ and $w R_{2}=9.92 \%$. The structure consists of copper paddlewheel units connected in two dimensions via carboxylate bridging ligands to provide a porous network. All copper centres and ligands are crystallographically equivalent and the material contains both hydrophilic and hydrophobic channels that run perpendicular to the Kagome lattice sheets. The hydrophilic pores are lined with coordinated water molecules and the hydrophobic pores are lined with dimethylamino side chains (Fig. 2).

The material is a member of the STAM series, previous members of which contain either a methyl ester side chain $\left(S T A M-1,{ }^{20}\right)$ or an alkoxy side (in the STAM- $n$ series ${ }^{21}$ ). The dimethylamino side chains in STAM-NMe $\mathrm{N}_{2}$ protrude into the hydrophobic pore in a similar manner, and are resolved to a single crystallographic site (Fig. 3a). The structure comprises parallel sheets, where the axial coordinated water molecules on the copper paddlewheel units participate in hydrogen bonding interactions with adjacent carboxylate oxygen atoms, creating a cross-linked structure (Fig. $3 b$ ). The sheet stacking within the material may be observed in Fig. 4.

Thermal gravimetric analysis was collected under air and shows a series of mass changes, where non-coordinated solvent molecules are first lost from the structure up to $125^{\circ} \mathrm{C}$, followed by coordinated water molecules up to approximately $200{ }^{\circ} \mathrm{C}$. This is followed by a large mass loss up to $300{ }^{\circ} \mathrm{C}$, corresponding to the dimethylamino groups. Framework stability is lost from approximately $350{ }^{\circ} \mathrm{C}$, where the material decomposes into residual copper oxide (Fig. 5).

Variable temperature PXRD was used to investigate the effect of dehydration on the structure of STAM-NMe $\mathrm{N}_{2}$ and was collected using Mo $\mathrm{K} \alpha_{1,2}$ radiation under vacuum (Fig. 6).

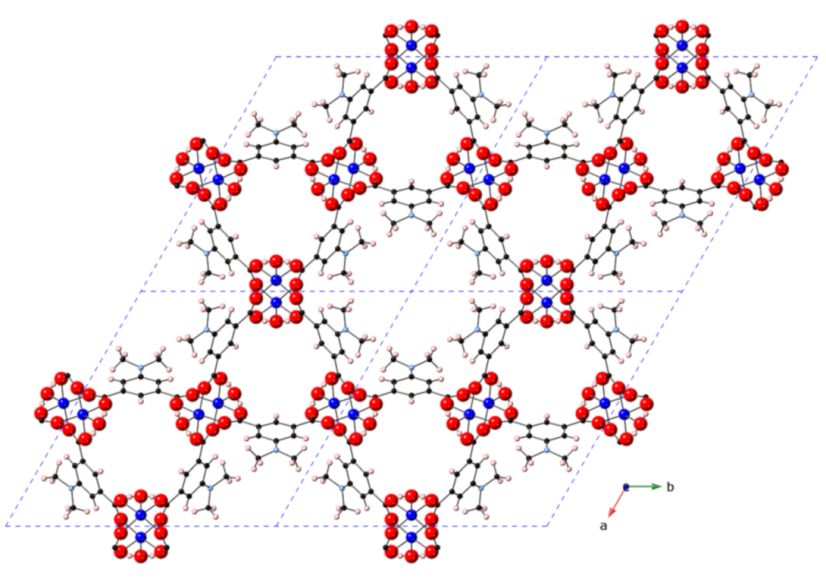

Fig. 2 Structure of STAM-NMe ${ }_{2}$, displaying the dual pore structure seen in the STAM series and a Kagome lattice structure. Key: dark blue: copper; red: oxygen; black: carbon; light blue: nitrogen; pink: hydrogen. 

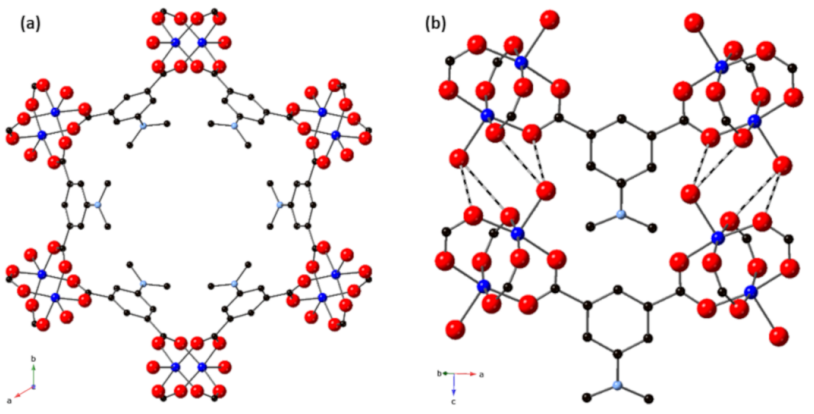

Fig. 3 (a) The hydrophobic pore in STAM-NMe the dimethylamino chains protruding into the pore and (b) Hydrogen bonding between adjacent copper acetate units. Key: dark blue: copper; red: oxygen; black: carbon; light blue: nitrogen. Hydrogen atoms have been omitted for clarity.

Half of the first peak is not visible due to its occurrence at approximately $1^{\circ} 2 \theta$, which could not be measured on the instrument. A pattern was first collected at $25^{\circ} \mathrm{C}$ in air to serve as a comparison for further collections under vacuum.

The structure is stable under vacuum at $25^{\circ} \mathrm{C}$, though begins to lose crystallinity at $50{ }^{\circ} \mathrm{C}$ when residual solvent molecules within the hydrophilic pores are lost. Near total loss of crystallinity is observed at $125{ }^{\circ} \mathrm{C}$, when water molecules coordinated to the copper acetate units are removed.

This low thermal stability is in contrast to another member of the STAM series: STAM-17-OEt, where crystallinity is retained throughout the measurement and after rehydration.

The loss of crystallinity even at low temperatures when under vacuum may be partially attributed to the lower stability of amines in relation to alkoxy substituents and it appears that the inclusion of an amine in the structure affects the structural stability of materials and causes the framework to collapse upon heating under vacuum.

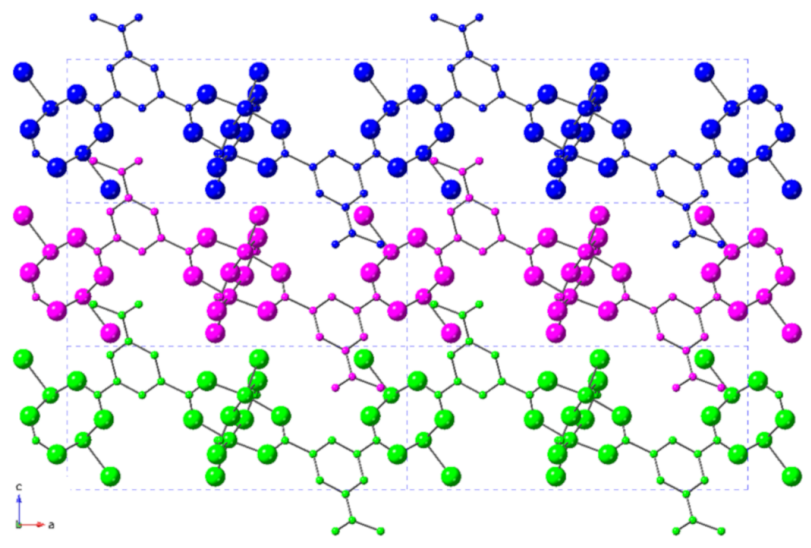

Fig. 4 Structure of STAM-NMe 2 viewed down the crystallographic $b$-axis showing sheet stacking in the material (coloured blue, pink and green). Hydrogen atoms have been omitted for clarity.

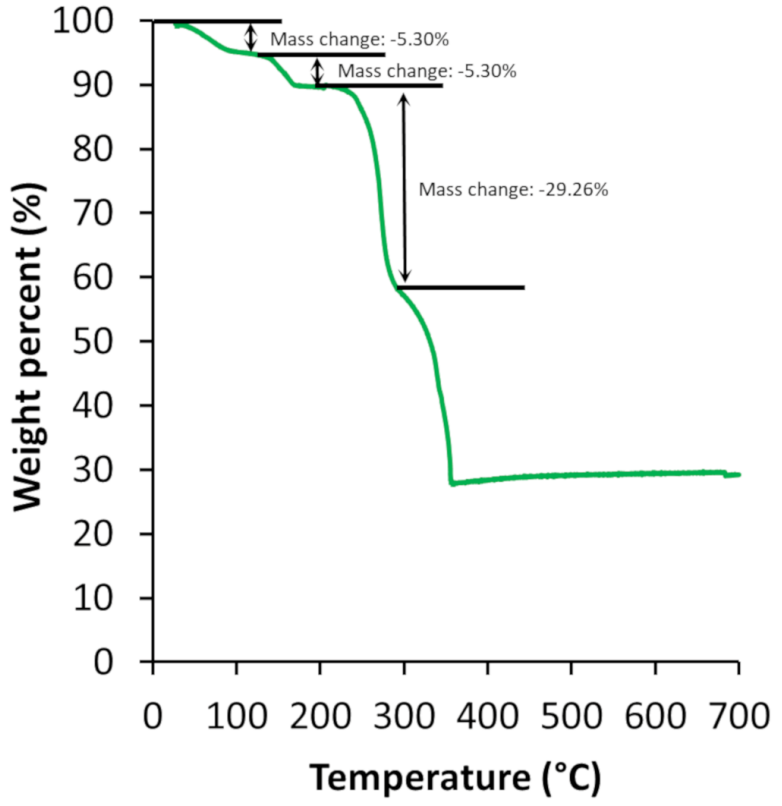

Fig. 5 TGA trace for STAM-NMe ${ }_{2}$ measured in air, showing the mass losses observed.

Due to the difficulty in observing a dehydrated phase in the material, it was consequently chosen to obtain nitrogen surface area measurements after activation under vacuum at $100{ }^{\circ} \mathrm{C}$, at which temperature some crystallinity was still visible in variable temperature PXRD and another surface area measurement where the material was not thermally activated prior to measurement (Fig. 7).

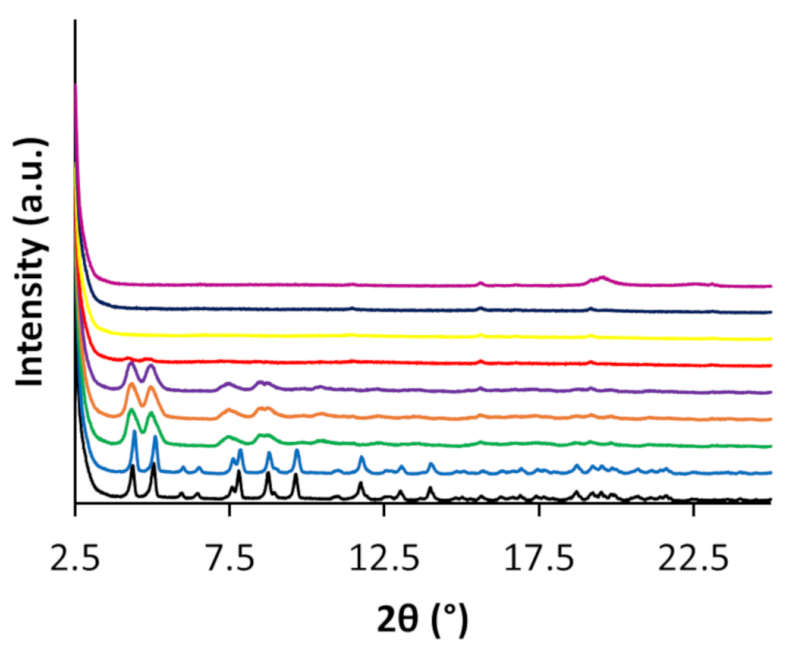



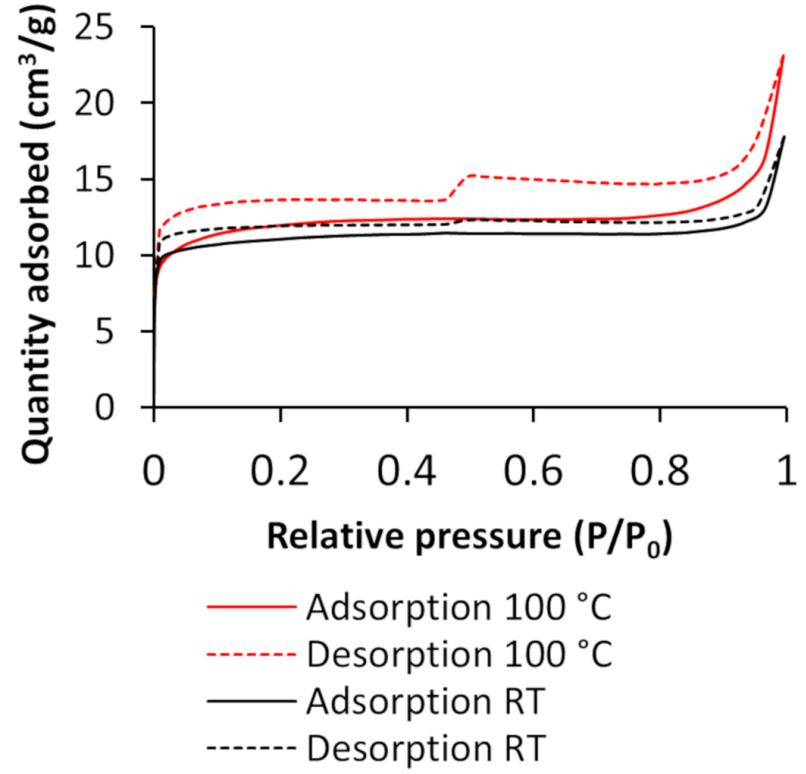

Fig. 7 Nitrogen adsorption isotherms for STAM-NMe samples pre-activated under vacuum at $100{ }^{\circ} \mathrm{C}$ and at room temperature. Both measurements were recorded at $77 \mathrm{~K}$.

The associated BET surface areas were $44.93 \mathrm{~m}^{2} / \mathrm{g}$ and 44.18 $\mathrm{m}^{2} / \mathrm{g}$ respectively, where pre-activation prior to nitrogen adsorption appears to have no effect on the porosity of the material. Such low surface areas are typical in STAM materials, with the related material: STAM-17-OEt displaying a BET surface area of $58 \mathrm{~m}^{2} / \mathrm{g}$. The low porosity is due to the limited access to nitrogen afforded at the experimental temperature of $77 \mathrm{~K}$ caused by a constriction of the pores.

\section{Conclusions}

A new member of the STAM series of copper MOFs: STAM$\mathrm{NMe}_{2}$ has been synthesised hydrothermally and was analysed by single crystal diffraction, variable temperature powder $\mathrm{X}$ ray diffraction and nitrogen BET surface area analysis. Crystals large enough for in-house single crystal X-ray diffraction were collected, where it was shown that STAM-NMe 2 has a Kagome lattice topology, with a dual pore system consisting of both hydrophilic and hydrophobic pores. Variable temperature powder X-ray diffraction showed that crystallinity in the material is lost upon activation under vacuum, which is contrary to what has been observed for others in the STAM series. While the material has STAM topology, it appears that the inclusion of a dimethylamino group within the structure impairs the thermal stability of STAM-NMe

\section{Conflicts of interest}

There are no conflicts to declare.

\section{Acknowledgements}

The authors would like to acknowledge the financial support from the EPSRC industrial CASE award (grant EP/N50936X/1). The authors would like to thank Dr. Yuri Andreev for his assistance in the obtainment of variable temperature PXRD data.

\section{Notes and references}

1 A. C. McKinlay, P. K. Allan, C. L. Renouf, M. J. Duncan, P. S. Wheatley, S. J. Warrender, D. Dawson, S. E. Ashbrook, B. Gil, B. Marszalek, T. Düren, J. J. Williams, C. Charrier, D. K. Mercer, S. J. Teat and R. E. Morris, APL Mater., 2014, 2, 124108.

2 P. K. Allan, P. S. Wheatley, D. Aldous, M. I. Mohideen, C. Tang, J. A. Hriljac, I. L. Megson, K. W. Chapman, G. De Weireld, S. Vaesen and R. E. Morris, Dalton Trans., 2012, 41, 4060-4066.

3 N. J. Hinks, A. C. McKinlay, B. Xiao, P. S. Wheatley and R. E. Morris, Microporous Mesoporous Mater., 2010, 129, 330334.

4 D. Ruano, M. Díaz-García, A. Alfayate and M. SánchezSánchez, ChemCatChem, 2015, 7, 674-681.

5 S. Wang, T. Cao, H. Yan, Y. Li, J. Lu, R. Ma, D. Li, J. Dou, J. Bai, Inorg. Chem., 2016, 55, 5139-5151.

6 X. Mi, D. Sheng, Y. Yu, Y. Wang, L. Zhao, J. Lu, Y. Li, D. Li, J. Dou, J. Duan and S. Wang, ACS Appl. Mater. Interfaces, 2019, 11, 7914-7926.

7 S. Yuan, Y.-K. Deng, D. Sun, Chem. Eur. J., 2014, 20, 10093 10098.

8 W. Fan, Y. Wang, Z. Xiao, Z. Huang, F. Dai, R. Wang, D. Sun, Chinese Chemical Letters, 2018, 29, 865-868.

9 D. Cattaneo, S. J. Warrender, M. J. Duncan, R. Castledine, N. Parkinson, I. Haley and R. E. Morris, Dalton Trans., 2015, 45, 618-629.

10 S. Chavan, J. G. Vitillo, E. Groppo, F. Bonino, C. Lamberti, P. D. C. Dietzel and S. Bordiga, J. Phys. Chem. C, 2009, 113, 3292-3299.

11 P. D. C. Dietzel, B. Panella, M. Hirscher, R. Blom and H. Fjellvåg, Chem. Commun., 2006, 9, 956-951.

12 J. B. Decoste and G. W. Peterson, Chem. Rev., 2014, 114, 5695-5727.

13 X.-P. Wang, W.-M. Chen, H. Qi, X.-Y. Li, C. Rajnák, Z.-Y. Feng, M. Kurmoo, R. Boča, C.-J. Jia, C.-H. Tung and D. Sun, Chem. Eur. J., 2017, 23, $7990-7996$.

14 Y. Chen, S. Zhang, S. Cao, S. Li, F. Chen, S. Yuan, C. Xu, J. Zhou, X. Feng, X. Ma and B. Wang, Adv. Mat., 2017, 29, 1601221-1601226.

15 Y. Bian, R. Wang, S. Wang, C. Yao, W. Ren, C. Chen and L. Zhang, J. Mater. Chem. A., 2018, 6, 15807-15814.

16 T. Grant Glover, G. W. Peterson, B. J. Schindler, D. Britt and O. Yaghi, Chem. Eng. Sci., 2011, 66, 163-170.

17 H. C. Zhou, J. R. Long and O. M. Yaghi, Chem. Rev., 2012, 112, 673-674.

18 H. Furukawa, K. E. Cordova, M O'Keeffe and O. M. Yaghi, Science, 2013, 341, 123044.

19 M. H. Rosnes, M. Optiz, M. Frontzek, W. Lohstroh, J. Peter Embs, P. A. Georgiev and P. D. C. Dietzel, J. Mater. Chem. A., 2015, 3, 4827-4839.

20 M. L. Tong and X. M. Chen, Synthesis of Coordination Compounds and Coordination Polymers. Modern Inorganic Synthetic Chemistry, 2nd ed., Cambridge: Elsevier, 2017, ch. 8, 189-217. 
21 A. C. McKinlay, B. Xiao, D. S. Wragg, P. S. Wheatley, I. L. Megson and R. E. Morris, J. Am. Chem. Soc., 2008, 130, 10440-10444.

22 S. R. Caskey, A. G. Wong-Foy and A. J. Matzger, J. Am. Chem. Soc., 2008, 130, 10870-10871.

23 P. K. Allan, P. S. Wheatley, D. Aldous, M. I. Mohideen, C. Tang, J. A. Hriljak, I. L. Megson, K. W. Chapman, G. de Weireld, S. Vaesen, and R. E. Morris, 2012, 41, 4060-4066.

24 G. W. Peterson, G. W. Wagner, A. Balboa, J. Mahle, T. Sewell and C. J. Karwacki, J. Phys. Chem. C., 2009, 113, 1390613917.

25 M. I. Mohideen, B. Xiao, P. S. Wheatley, A. C. McKinlay, Y. Li, A. M. Z. Slawin, D. W. Aldous, N. F. Cessford, T. Düren, X. Zhao, R. Gill, K. M. Thomas, J. M. Griffin, S. E. Ashbrook and R. E. Morris, Nat. Chem., 2011, 3, 304-310.

26 L.N. McHugh, M. J. McPherson, L. J. McCormick, S. A. Morris, P. S. Wheatley, S. J. Teat, D. McKay, D. M. Dawson, C. E. F. Sansome, S. E. Ashbrook, C. A. Stone, M. W. Smith and R. E. Morris, Nat. Chem., 2018, 10, 1096-1102.

27 CrysAlisPRO, Oxford Diffraction /Agilent Technologies UK Ltd, Yarnton, England.

28 G. M. Sheldrick, Acta Crystallogr A, 2015, 71, 3-8.

29 G. M. Sheldrick, Acta Crystallogr C, 2015, 71, 3-8.

30 O. V. Dolomanov, L. J. Bourhis, R. J. Gildea, J. A. K. Howard and H. Puschmann, J. Appl. Crystallogr., 2009, 42, 339-341.

31 A. C. Larson and R. B. Von Dreele, "General Structure Analysis System (GSAS)", 2000, Los Alamos National Laboratory Report LAUR, 86-748.

32 B. H. Toby, Appl. Cryst., 2001, 34, 210-213.

33 I. Syôzi, Prog. Theor. Phys., 1951, 6, 306-308. 